ON THE THEORIES OF HOST-PARASITE I N T E R A C T IONS

by

H. KLOMP

(Institute for Applied Biological Field Research, Arnhem, Holland) 


\title{
ON THE THEORIES OF HOST-PARASITE
}

\section{N T E R A C T ION S 1}

\author{
by \\ H. KLOMP2 \\ (Institute for Applied Biological Field Research, Amhem, Holland)
}

During the last century Howard ( 1897 ) pointed out the significance of insect parasites in the natural regulation of their hosts. In the first quarter of this century HowARD's opinion has been corroborated by the success of several biological control operations (CLAUSEN, I95 I). On the other hand the introduction of parasites does not always succeed in reducing host density to a level low enough to eliminate economic damage. Moreover, in forests where insects, normally living at a low density level, are liable to increase to infestation proportions, indigenous parasites are sometimes found to play only a small part in control at the higher densities. In such cases parasites do not appear able either to prevent infestation in the first place, or to cause significant reduction in host numbers once the outbreak has taken place.

Hence, the part played by parasites in the biological or natural control of their hosts is not always evident. There seem to be certain conditions under which their regulatory capacity is limited. On the whole, however, it is generally assumed that parasites are important controllers of host numbers (HALDANE, r953) though it must be admitted that this assumption is but poorly supported by reliable field work. In my opinion the most logical support may be found in the clear reasoning of Nrcholson in his theory of host-parasite interaction, the premises of which are still to be proven.

Two important theories of host-parasite interaction have been stated, those of THOMpson (1922-24) and of Nicholson (1933). The latter has been formulated mathematically by Nicholson and BAILY (1935).

I Paper discussed at the Congress of I.U.F.R.O., Oxford 1956, with some modifications added.

2 Present address: Zoological Laboratory, Agricultural University, Wageningen, Holland. 
Thompson's theory makes the initial assumption of a parasite-host relationship within which both host and parasite lay a fixed number of eggs (power of increase $h$ and $s$, respectively). Starting from definite initial host and parasite densities ( $\mathrm{n}$ and $\mathrm{p}$, respectively) their numbers $\left(G_{t}\right.$ and $\left.P_{t}\right)$ after $t$ successive generations may be expressed arithmetically. Assuming $h$ and $s>I$, both the host and parasite have increased in numbers after $t$ generations. When $G_{t}=P_{t}$, the parasite will kill all the hosts. This is so when

$$
t=\frac{\log \frac{n a-n+p a}{n a}}{\log a}, \text { where } a=\frac{s}{h}
$$

In this function $t$ has a real value only when na $+p a>n$, and therefore when $p / n>\frac{h-s}{s}$. In other words the host will be eliminated (the percentage parasitism will increase) upon this supposition. If $\mathrm{p} / \mathrm{n}<\frac{\mathrm{h}-\mathrm{s}}{\mathrm{s}}$ then the host and parasite will multiply in geometric progression to infinity, and the percentage parasitism will go on decreasing. Tномрson mainly applies his theory to phenomena observed in biological control operations, and with certain reservations, it may be used to explain both the successes and the failures of this method as a means of control. Biological control, however, never results in complete elimination of the host. Once the parasite is established the host density is reduced to a level where economic damage no longer occurs, and at this level host and parasite live together in the same habitat, and their populations are in a state of fluctuating balance. Thompsos's theory does not provide any form of a state of balance. A theoretical 'steady state', where the parasite kills as many hosts as needed to maintain the population of host and parasite unchanged, is only possible when $\mathrm{p} / \mathrm{n}=\frac{\mathrm{h}-\mathrm{s}}{\mathrm{s}}$ and, in addition, the number of eggs laid per parasite individual is extremely small $(s=1)$ (neglecting the sex for the sake of simplification). Such a situation may be rejected as impossible because there are no parasites known with so low a fecundity. In addition, the existence of a host attended by a single specific parasite and uninfluenced by any other mortality factor, as assumed by Thompson, is very unlikely to occur in nature. The system will always be more complex and thus more applicable to phenomena actually observed under field conditions.

In such a relatively complicated system a steady state can exist in theory when the mortality factors account for a constant percentage 
of the populations. In nature, however, the influence of mortality factors changes from generation to generation, and it will be interesting, therefore, to consider what happens under such conditions. In these considerations we must differentiate between mortality factors affecting either the host or the parasite (specific factors), and those affecting the host and parasite indiscriminately (non-specific factors). Factors of the latter type normally eliminate parasitized and nonparasitized hosts to the same relative amount.

When a specific mortality factor kills a constant percentage of hosts, the number of eggs laid by the parasite must still be I for the steady state to exist. It appears from the example given below, that such an equilibrium is very unstable, for when the mortality factor changes its influence on the population once (i.e. on I generation), the steady state is disturbed. The result is either extermination or, alternatively, infinite increase of the host, because in the first case $\frac{p}{n}>\frac{h-s}{s}$ and in the second $\frac{\mathrm{p}}{\mathrm{n}}<\frac{\mathrm{h}-\mathrm{s}}{\mathrm{s}}$ (cf p. I35). In both cases the parasite will be incapable of increasing its numbers.

E.g. $n=40, p=10, h=5$ and $s=\dot{1}, \frac{p}{n}=\frac{h^{1}-s^{*}}{s}$

With specific mortality operating at $75 \%$, and changing once to $80 \%$ (a) and $70 \%(b)$ :

Steady state: hosts, $40 \times 5=200$; survival $25 \%=50$

parasites, $10 \times 1=10$

40 host

10 parasite

(a) extermination of the host

$40 \times 5=200$, survival $20 \%=40$

$10 \times 1=$

$\frac{10}{30}-$

$30 \times 5=150$, survival $25 \%=37,5$

$10 \times 1=$

$\frac{1011}{27.5}-$, because $\frac{p}{n}=\frac{1}{3}>\frac{h^{1}-1}{I}=\frac{1}{4}$

(b) infinite increase of the host

$40 \times 5=200$, survival $30 \%=60$

$10 \times 1=$

$$
\frac{10}{50}-
$$

$50 \times 5=250$, survival $25 \%=62.5$

$10 \times 1=$

$$
\frac{10}{52.5}, \text { because } \frac{\mathrm{p}}{\mathrm{n}}=\frac{\mathrm{I}}{5}<\frac{\mathrm{h}^{1}-\mathrm{s}}{\mathrm{s}}=\frac{\mathrm{l}}{4}
$$

* Virtually through the operation of the mortality factor the host's power of increase is reduced to $25 \%$ of its original value. Instead of $5(=h)$ only $1.25\left(=h^{1}\right)$ offspring are produced per host individual. 
The defect of the theory is also clear when a non-specific mortality factor operates. When this factor kills a constant percentage of parasitized and non-parasitized hosts, the number of eggs laid by the parasite must be greater than I for the steady state to exist. From the number of hosts parasitized by one parasite individual I must survive, the surplus being destroycd by the mortality factor. However, such an cquilibrium is unstable as well, for when the factor changes its influence once, the steady densities will be higher than the original when mortality is reduced and lowered when mortality increases. In contrast with the foregoing example new steady densities will be maintained because the proportion $\mathrm{p} / \mathrm{n}$ does not change (cf $\mathrm{p}$. I35).

E.g. $n=40, p=10, h=25, s=20, \frac{p}{n}=\frac{h-s}{s}$

With non-specific mortality opcrating at $95 \%$, and changing once to $80 \%$ (a) and $99 \%$ (b):

Steady state: $40 \times 25=1000$, hosts

$$
\begin{aligned}
& 10 \times 20=200 \text {, parasites } \\
& 800 ; 5 \% \text { survival }=40, \times 25=1000 \\
& 200 ; 5 \% \text { survival }=10, \times 20=200 \\
& \frac{200}{800}-
\end{aligned}
$$

(a) mortality reduced $800 ; 20 \%$ survival $=160, \times 25=4000$ $200 ; 20 \%$ survival $=40, \times 20=800$

$$
\begin{array}{r}
3200 ; 5 \% \text { survival }=160 \\
800 ; 5 \% \text { survival }=40
\end{array}
$$

(b) mortality increased

$800 ; 1 \%$ survival $=8, \times 25=200$

$200 ; 1 \%$ survival $=$

$$
\begin{aligned}
2, \times 20=\frac{40}{160 ; 5 \% \text { survival }=} & 8 \\
40 ; 5 \% \text { survival }= & 2
\end{aligned}
$$

Under field conditions we may expect that the percentage killed by a mortality factor changes from generation to generation and fluctuates around a mean value. If this value is such, that the condition for balance, $\frac{p}{n}=\frac{h+s}{s}$, is satisfied, and each parasite leaves one offspring in average we might logically assume that the parasite and host populations would be held in a state of fluctuating balance. Arithmetical consideration, however, lead us to the conclusion that in such a situation the parasite is unable to kecp the population of the host in balance.

When a fluctuating specific mortality factor operates the result will be the same as with a specific factor changing its influence once (cf. example 1): either extermination or infinite increase of the host. The 
result is depending on the type of the first disturbance of the steady state. When the mortality is reduced and, consequently, the host density is increased, so that $\frac{p}{n}<\frac{h-s}{s}$, the host will go on increasing. This increase can only be stopped by a high mortality, which reduces the host density to a level lower than the steady density. Then $\frac{p}{n}>\frac{h-s}{s}$, and the host will go on decreasing in numbers, unless by a considerable fall in mortality the host density again rises to a level higher than the steady density. This return to intermediate densities may accidentely occur by a random fall or rise in mortality when host density has not yet reached a too extreme value. Long term fluctuations, however, can only occur when the mortality factor is density dependent. In this case the population density is regulated by the mortality factor and the parasite has no regulating effect.

When a fluctuating non-specific mortality factor operates the parasite likewise is unable to keep the population in balance. When the mortality fluctuates around a mean value the population always decreases.

E.g. $n=40, p=10, h=25, s=20, \frac{p}{n}=\frac{h-s}{s}$

With non-specific mortality operating at $95 \%$ in average, and fluctuating at $92 \%$ $97 \%, 93 \%$ and $98 \%$ in successive generations:

Steady state, see foregoing example

800 hosts $\quad ; 8 \%$ survival $=64, \times 25=1600$

200 parasites; $8 \%$ survival $=16, \times 20=320$

$$
1280 \text { hosts }
$$

$1280 ; 3 \%$ survival

$320 ; 3 \%$ survival

$768 ; 7 \%$ survival

$192 ; 7 \%$ survival

$1077 ; 2 \%$ survival

$268 ; 2 \%$ survival

$$
\begin{aligned}
& =38.4, \times 25=960 \\
& =9.6, \times 20=\frac{192}{768 \text { hosts }}
\end{aligned}
$$$$
\begin{aligned}
& =53.8, \times 25=1345 \\
& =13.4, \times 20=268
\end{aligned}
$$

1077 hosts

$$
\begin{aligned}
& =21.5, \times 25=538 \\
& =5.4, \times 20=\frac{108}{430 \text { hosts }}
\end{aligned}
$$

Because the mortality factor affects the host and parasite indiscriminately the proportion $\frac{p}{n}$ and, consequently, the percentage of parasitism do not change. In the above example the number of non-parasitized hosts can be calculated in each 
generation as 0.80 times its initial number. Therefore, in the steady state the numbers of the host surviving the mortality factor and the parasite during two generations are as follows:

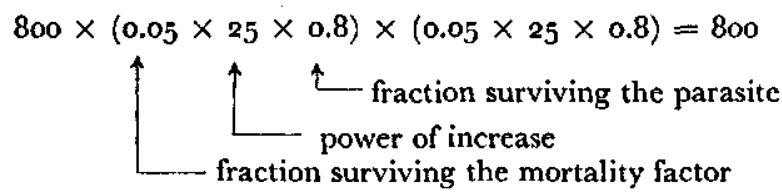

When the mortality factor fluctuates around the mean value of 0.95 (say 0.92 and $0.9^{8}$ in two successive generations) the numbers of the host run as follows:

$800 \times(0.08 \times 25 \times 0.8) \times(0.02 \times 25 \times 0.8)=512$

Because $0.05 \times 0.05>0.08 \times 0.02$, or, in general $\mathrm{a}^{2}>(\mathrm{a}-\mathrm{p})(\mathrm{a}+\mathrm{p})$, the host density always decreases.

Thus Trompson's theory does not in fact provide a basis for a hostparasite system in fluctuating balance, owing to the assumption that the number of eggs laid by a parasite is unrelated to host density. If this assumption is made in a parasite-host system within which specific or non-specific mortality factors are operating, disturbance of the steady state leads to infinite increase of the host or to extermination. Moreover, it seems highly improbable that, at very low host densities, a parasite individual would be capable of finding the hosts necessary for deposition of all its eggs. We might expect this to occur only at really high host densities (p. 141 ).

Nicholson's theory starts with the assumption that only the host produces a fixed number of progeny, the number of eggs laid by the parasite being dependent on host density. Nicholson further claims that parasites search at random and thus the probability of finding a host is proportional to host density.

The capacity of a parasite to find its host is referred to as the area of discovery, and may be defined as the area effectively searched during the lifetime. It is the area within which all hosts have been found and parasitized. The number of hosts parasitized is high when host density is high and low when the density is low. The searching capacity, and hence the area of discovery of a parasite, is dependent on the keenness of its senses and its efficiency in capture. Thus an active parasite with keen senses will find more hosts of a definite species and will have a larger area of discovery.

The fraction of hosts parasitized (named the area covered) by a certain parasite is independent of host density. Though this fraction increases when the number of parasites increases, the rise is not proportional to the parasite density because the areas traversed by different individuals overlap more and more as parasite density increases. Thus, there is an increasing probability for a parasite individual to 
find a host already parasitized with rising parasite density and those hosts will be avoided by selective parasites or parasitized again by non-selective or superparasites. The relationship between fraction parasitized ( $=$ area covered $=$ percentage parasitism) and parasite density (expressed as the area traversed by the total parasite population) is an e-function, the graph of which is named the competition curve (see Nicholson, 1933). When values for the area of discovery of the parasite and the power of increase of the host are known, a steady state for the insects can be calculated. As already mentioned above such a simple example is unlikely to exist in nature but it is possible to introduce all kinds of specific and non-specific mortality factors into it. Such introductions change the steady densities but otherwise will not disturb the state of stationary balance. Under field conditions, as above mentioned, a stationary balance cannot occur because the mortality factors will never be constant, and therefore this balance, assuming that it did once exist, is immediately upset. However, in a Nicholson system the reaction of the parasite to the disturbance is basically different from its behaviour in a Thompson system. When the change in influence of the mortality factor results in an increase in host density, the parasite's chance to find a host is increased and consequently more eggs are laid; this leads to a reproduction excess and an increase in parasite density in the next generation(delayed density dependent: VARLEY 1947). In this generation a greater fraction of hosts is eliminated and this is repeated in subsequent generations until the host's mortality exceeds its reproduction. Due to the delay in effect the parasite is still very numerous even though the host has decreased in numbers and, thus, host density falls far below the steady density which, in turn, causes a greater reduction in parasite numbers. The host will then recover again, but, due to the scarcity of the parasite, will reach much higher numbers than in the previous oscillation. In fact, the delay in the effect of the parasite causes oscillations with increasing amplitude. Thus Nicholson's theory, too, fails to provide a basis for a self-regulating system. In theory an interaction with increased oscillation always leads to a peak, followed by a crash to a very low population density. Nicholson claims that when such a situation has been reached the densities are maintained much below their steady values, the animals being distributed in small groups. However, under field conditions, there are many host-parasite systems not characterized by these phenomena.

There is very little field evidence to support NichoLson's theory. VARLEY (1947) has shown that the fecundity of the chalcid Eurytoma curta, a parasite of the gall fly Urophora jeceana, was reduced by a fall in host density. Estimates of the area of discovery of the parasite for 
two years were $0.3 \mathrm{I}$ and $0.19 \mathrm{sq} . \mathrm{m}$, but the difference is not significant, and moreover, the latter value may show inhibition of the parasite by cold weather.

All further evidence is from experimental work. BURNETT (I95I), de Bach and SMith (I94I), and Flanders (I935) have shown in experimental populations that the number of hosts parasitized per parasite increased with increase in host density. Flanders (l.c.) concluded from his work with the egg parasite Trichogramma that increase in fecundity reaches a maximum at a definite host density owing to the limited egg-laying capacity of the parasite. Thus over a part of the range of host densities Nicholson's theory applies. When host density is very high the influence of the parasite may be limited by egg supply, and at this density level Thompson's theory holds. This has already been pointed out by VARLEY (1947).

Egg production in Hymenoptera has been studied by Flanders (1942). He showed that in some species production of ripe eggs continues throughout the life of the parasite as long as there are hosts enough for oviposition. When oviposition is inhibited oogenesis may continue but ovulation ceases, and the ripe eggs in the ovarioles are resorbed. Some ripe eggs, however, are always present and, as in species which store ripe eggs in the uterus, oviposition may take place at any time hosts are offered. These mechanisms may be considered as adaptations for maintaining the reproductive capacity when environmental conditions are unfavourable for oviposition. The results from FLANDER's work provide a good argument in favour of Nicholson's theory, for in some Hymenoptera the number of ripe eggs produced appears to be highly dependent on host density so that their fecundity cannot be constant. In other species a definite number of eggs is produced a.o. Trichogramma (Flanders) and, probably, also in many Tachinidae. In these species we may expect that Nicholson's theory will hold over a definite part of the range of host densities. When host density is very high the parasite will be limited by egg supply and under such conditions THOMPson's theory will be valid.

According to the above arguments we may conclude that Nicholson and Thompson's theories are not antagonistic. They are both applicable but at different densities of the host.

It has already been pointed out that neither theory provides a sound basis for a self-regulating host-parasite complex. NicHolson, however, offers a better starting point than does Thompson. In the former any disturbance of the steady state by a changing specific or non-specific mortality factor included in the system gives rise to regular oscillations about the steady state. In the latter every disturbance of the steady state by a specific or non-specific factor leads to unlimited increase or 
to extermination. Regular oscillations, inherent in Nicholson's thcory of parasite-host relationships, cannot exist under actual field conditions because of the changing environmental factors working within the system. This does not mean that Nicholson's assumptions cannot be realized in nature. The main objection which may be levelled against his theory is the ever-increasing amplitude of the oscillations, which has never been observed in nature. DE BACH and SMITH (I94I) have shown experimentally that this effect can, in fact, occur in a hostparasite relationship, but the conditions under which their experiments were carried out were so artificial that the results should be regarded with reservation.

In the literature several mechanisms with damping effect have been mentioned on purely theoretical grounds. NICHOLSON himself suggests as an example one parasite with two or more hosts, one of which is regulated by the parasite and the others by other factors. The density of the parasite then is, in part, determined by its other host(s) and consequently the violence of its effect on the regulated host is reduced. This leads to oscillations with decreasing amplitude. VARLEY (1947) claims that the oscillations may be damped if some of the hosts are less available to the parasite than others, and this may be so due to the irregular distribution of the host.

De BACH and Smith have pointed out that the oscillations may be damped by a strongly density dependent reproduction. However, they realize... 'that where an enemy really had a decided depressing influence on the population density of its host, the point in host density at which the latter limits its own reproductive rate is not ordinarily attained'. Under experimental conditions this point in density may be reached, as shown by UTIDA (1950), in populations of Callosobruchus chinensis and its larval parasite Heterospilus prosopidis. Here the host is prevented from reaching extremely high densities by its own decreasing fecundity and fertility.

The mechanism of damping was thoroughly investigated by the late L. TINBERGEN ${ }^{1}$. Very briefly he reviewed his ideas in a lecture published in 1955 and in which he considered three ways in which damped oscillations may be introduced into a NicHOLson-system.

I. That given by Nichosson himself and which has already been mentioned. In this example the density of the host not regulated by the parasite is independent of the activity of the parasite and remains constant. In nature such a situation can not be, and we must interpret Nicholson to mean that fluctuation in host numbers is not caused by the parasite whose influence is counteracted by the regulating mechan-

1 His conclusions are summarized here at the request of the discussion group on population - dynamics of the $24^{\text {th }}$ Section of I.U.F.R.O. 
ism of the host itself. However, when there are high densities of the parasite owing to large numbers of the regulated host, it is very unlikely that the regulating mechanism of the second host will be able to counterbalance a high mortality.

2. Density dependent reproduction of the host. TINBERGEN has shown arithmetically that a strongly inverse density dependent reproduction of the host results in damped oscillations in any host-parasite system. Therefore fecundity and fertility must fall greatly at density levels normally occurring in natural populations. TINBERgEN, as did DE BACH and SMITH (I94I), realized that density dependent reduction of fecundity at these relatively low densities is very unlikely to exist in actual fact. It has been shown by MORS (1942) that at the very high densities present during an infestation of the Nun Moth, Lymantria monacha, both the fecundity of the female and the power of copulation of the male were reduced.

3. Density dependent mortality of the host. In theory density dependent mortality, as in the case of reproduction, proves to have a damping effect, provided that the factor involved plays an important part in mortality at intermediate densities of the host. This condition is much more likely to exist in nature. Having once established this, TinBERgEN proceeded to combine his theory with facts gained in his studies on mortality in caterpillar populations caused by titmice. He measured percent predation of several caterpillar species at various densities over a number of successive years. At lower hos densities mortality proves to be density dependent in the sense that SMITH uses this term (1935). At higher densities mortality appeared, however, to be inversely density dependent in the sense given by Solomon (1949). Thus the relation between prey density and percent predation will have the appearance of an optimum curve.

The density dependent effect is due to the development of a preference by the titmice for prey species at intermediate densities (the biological significance being an increase of efficiency in foraging). At low densities of the prey this preference does not develop because, at such levels of population, the rarity of the prey makes a specific search an inefficient method.

TINBERGEN combincd the empirically determined optimum curve of particular prey species (Panolis and Acantholyda) with a Nicholsonparasite - host complex and he concluded that the density dependent effect at lower densities causes damped oscillations.

Hence, in theory, a combination of bird and parasite predators on a common host provides a very good example of a self-regulating system. It is probable that the role given to birds in the above example may be taken up by other factors in habitats where birds are rare or absent. 
TINBERGEN's studies have stressed the great value of Nicholson's theory. The conclusions he reached should act as a strong stimulus to further investigation into the interaction of host and parasite, and to test the correctness of Nicholson's basic assumptions under field conditions. VARLEY's work on Urophora jaceana and its parasites shows clearly how best to set out on field work of this type, in spite of MILNE's (1957) criticism on its statistical methods and mathematical considerations. This criticism is partly right, but in fact does very little derogation to the general line of thought and the way of planning population dynamic field work. It is essential to obtain host and parasite density and percentages of parasitism over a period of generations. Forests are particularly suited to this type of investigations, owing to their comparative constancy of condition from year to year, and to their usually simple homogeneous plant composition. Therefore forest entomologist's seem to have a special task in this field of ecology.

\section{SU M MARY}

The theories of host-parasite interactions of THOMPSON and NrGHoLson are discussed. The first theory makes the initial assumption that both host and parasite lay a fixed number of eggs. Nicholson, on the other hand, assumes that only the host produces a fixed number of progeny, the number of eggs laid by the parasite being dependent on host density.

Further, both theories assume that the host is attended by a single specific parasite (THOMPSON and Nicholson) or more, and also nonspecific (polyphagous) parasites (NICHOLSON). In nature, however, the system will always be more complex and both host and parasite will be influenced by other mortality factors. Moreover, the effect of these factors changes from generation to generation.

When fluctuating mortality factors operate in a THOмPSON parasitehost system the inevitable disturbance of the steady state leads to infinite increase of the host or to extermination, the result being dependent on the properties of the mortality factor. This is illustrated in the text with some arithmetical examples. Thus, Thompson's theory does not in fact provide a basis for a host-parasite system in fluctuating balance, owing to the initial assumption that the number of eggs laid by the parasite is fixed and unrelated to host density.

When fluctuating mortality factors are included in a NichoLson parasite-host system the reaction of the parasite causes oscillations with increasing amplitude. This leads to a peak, followed by a crash to a very low density. However, under field conditions, there are many host-parasite systems not characterized by this phenomenon. 
In the literature several mechanisms damping the increasing amplitude inherent to a Nicholson system have been mentioned on theoretical grounds. The most interesting is that given by L. TINBERGEN. He measured percent predation caused by titmice in caterpillar populations at various densities over a number of successive years. In the range from low to intermediate densities of the prey mortality proved to be density dependent. When this empirically determined effect is combined with an arithmetical Nicholson host-parasite system it results in damped oscillations.

Hence, in theory, a combination of bird and parasite predators on a common host provides a very good example of a self-regulating system.

\section{REFERENCES}

BURNETT, TH., 1951: Effects of temperature and host density on the rate of increase of an insect parasite. Amer. Nat., 85, 337-352.

Clausen, C. P., r951: The time factor in biological control. J. econ. Ent., 44, I-8.

De BAck, P. and H. S. Sмiтh, 1941: Are population oscillations inherent in the host-parasite relation? Ecol., 22, 363-369.

FLanders, S. E., 1935: Effect of host density on parasitism. J. econ. Ent., 28, 898-900.

Flanders, S. E., 1942: Oösorption and ovulation in relation to oviposition in the parasitic Hymenoptera. Ann. Ent. Soc. Amer., 35, $251-266$.

Haldane, J. B. S., I 953: Animal populations and their regulation. New Biol., 15, 9-24.

HoWARD, L. O., 1897: A study in insect parasitism: A consideration of the parasites of the White-marked Tussock Moth, with an account of their habits and interrelations and with descriptions of new species. Tech. Ser. U.S. Dept. Agr., 5, 5-57.

Milne, A., 1957: The natural control of insect populations. Can. Ent., 89, 193-213.

MoRs, H., 1942: Der Nonnenfalter während einer Massenvermehrung. In: Die Nonne in Ostpreussen (1933-1937). Monogr. Angew. Ent., 15, 176-205.

Nicholson, A. J., 1933: The balance of animal populations. J. anim. Ecol., 2, $132+178$.

Nicholson, A. J. and Baily, V.A., 1935: The balance of animal populations. Part I. Proc. Zool. Soc. London, 551-598.

SмIтH, H. S., I935: The role of biotic factors in the determination of population densities. J. Econ. Ent., 28, 873-898.

Solomon, M. E., I949: The natural control of animal populations. J. anim. Ecol., 18, $1-35$.

Tinbergen, L., 1955: Onderzoek over de dynamiek van insecten bevolkingen in Veluwse bossen. Akademie-dagen Kon. Ned. Acad. Wetensch. Amsterdam, 8, 140-1 49 .

Thompson, W. R., 1922: Théorie de l'action des parasites entomophages. C. R. Acad. Sci. Paris 174, I 20I-1 204, 1433-1435, 1647-1649, 175, 65-68.

Thompson, W. R., 1923: La théorie mathématique de l'action des parasites entomophages. Rev, gen. Sci. par. appl., 11 pp.

Thompson, W. R., 1924: Théorie mathématique de l'action des parasites entomophages et le facteur du hasard. Ann. Fac. Sci. Marseille, 2, 69-89.

UTIDA, S., 1950: On the equilibrium state of the interacting population of an insect and its parasite. Ecol, $31,165^{-175}$.

VARLEY, G. C., 1947: The natural control of population balance in the knapweed Gall-fly (Urophora jaceana). J. anim. Ecol., 16, 139-187. 